\title{
Numerical simulation of atomization and combustion characteristics of high-moisture organic wastewater
}

\author{
Jing Ding ${ }^{1, a^{*}}$, Qiang Tang ${ }^{2, b}$ and Tengfei Zhang ${ }^{3, c}$ \\ ${ }^{1}$ School of Energy and Power Engineering, Chongqing University, Chongqing, China \\ ${ }^{2}$ School of Energy and Power Engineering, Chongqing University, Chongqing, China \\ ${ }^{3}$ School of Energy and Power Engineering, Chongqing University, Chongqing, China
}

\begin{abstract}
The combustion method, due to its convenience and high-efficiency in harmless treatment, has been widely used in disposal of wastewater. With a wastewater burner as the study case, we performed numerical simulation by the Fluent software, analyzed the flowing and combustion process of the wastewater samples in the burner, compared the combustion effect of different atomization conditions the spray cone model (hollow cone model, solid cone model), the spray angle, non-uniform grain size, uniform grain size. The study aims to provide suggestions for design and selection of wastewater burners.
\end{abstract}

\section{Introduction}

Combustion disposal has salient performance in treatment of high-moisture wastewater: it can efficiently remove the pollutants in organic wastewater, but is ecofriendly as it can recycle energies. Having gained rapid development in these years, this technique enjoys a great prospect of application. The atomization characteristics of the burner are an important factor for design of the burner. Through numerical simulation, we explored the atomization and combustion characteristics of wastewater, analyzed the influencing factors and control variables of the combustion process, with a vision to improve the design and promote the application of wastewater burners.

\section{Physical model and grid partitioning}

The wastewater burner equipped on the wastewater combustion comprehensive testbed as the study object is used as the study object of this study [1]. To reduce the complexity of the grid, the structure of the burner is converted into a concentric jet stream surface, where the centric circle is the wastewater inlet (direct flow), and the centric annulus is the inlet of air and combustion gas (swirl flow). The rear of the burner chamber is set as a tapered outlet. There are 1.5 million grids in the computational domain, the range of the grid size is $7.91 \mathrm{e}-05$, which meets the requirements for calculation.

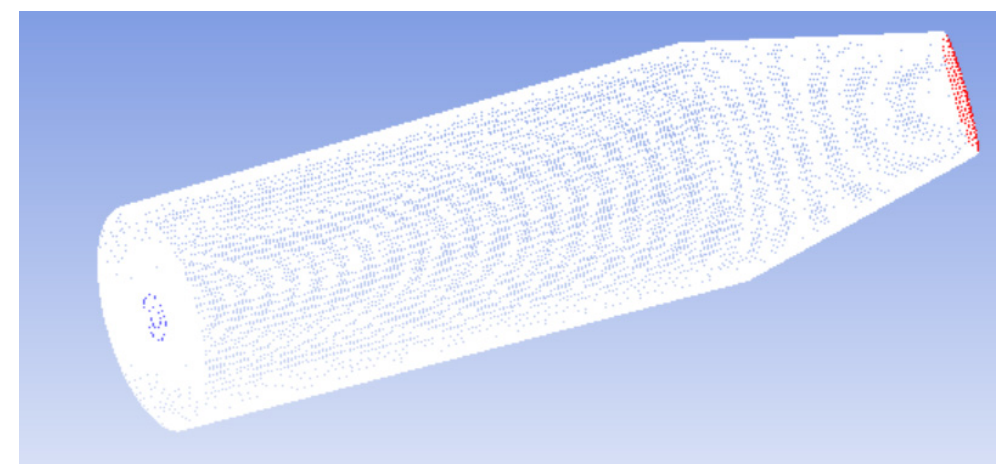

Figure 1. Geometric model of the burner and the grid partitioning diagram of the burner chamber

\section{Mathematical model and the fuel component}

The RNG k- $\varepsilon$ turbulent equation and the conservation equations for mass, energy, momentum and chemical components are employed to describe the flowing and combustion process [2]; the discrete-ordinate (DO) model is employed to simulate the radiation heat transfer in the burner chamber; the eddy-dissipation model (EDM) is employed to predict the reaction rate of the combustible gas mixture [3]; the SIMPLEC algorithm is employed to solve the fluid flow in the flow field[4]. 
The designed wastewater components are provided by a company. The gross heating value is $5438 \mathrm{~kJ} / \mathrm{kg}$, and the low heating value is $3432 \mathrm{~kJ} / \mathrm{kg}$. The industrial analysis result (as received basis) is shown in Table 1.

Table 1. Industrial analysis result of the wastewater sample (as received basis)

\begin{tabular}{ccccc}
\hline Term & moisture & Volatile matter & Fixed carbon & Ash content \\
\hline Value (\%) & 57.35 & 18.62 & 0.55 & 23.48 \\
\hline
\end{tabular}

The sample is high-moisture organic wastewater, with a low heating value. As it is difficult for ignition and stable combustion, combustion-supporting gases are needed to be added to ensure the combustion efficiency. The methane is employed as the combustion-supporting gas in this study. Simulations are made on the four factors: the spray cone model (hollow cone model, and solid cone model), the spray angle, non-uniform grain size, uniform grain size.

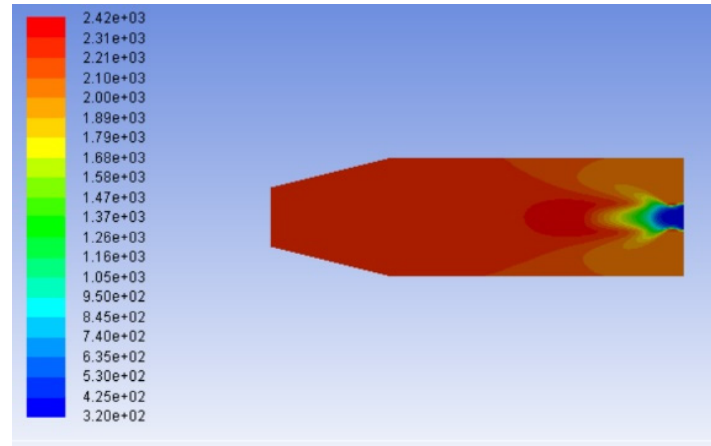

Figure 2. Temperature nephogram (hollow cone model)

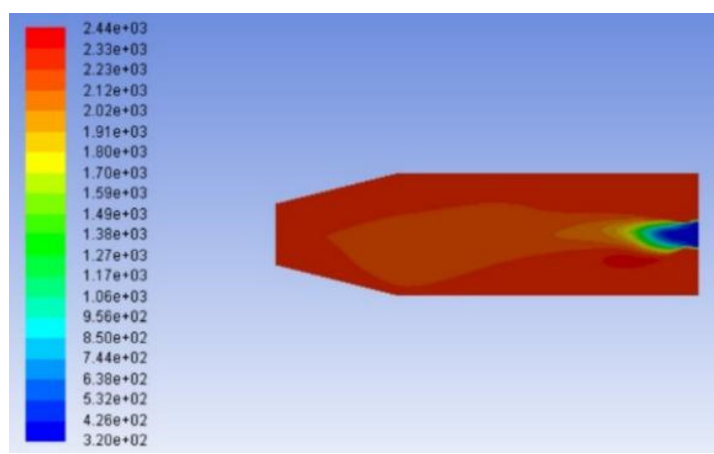

Figure 4. Temperature nephogram (solid cone model)

The difference between the solid cone and the hollow cone is whether there is jet flow inside the cone. Though the temperature and flow field distribution in the solid cone model is not as symmetric as in the hollow cone model, the solid cone model inside the liquid spray is much like a complete cone, the temperature transfer and flow are stable, and it is unlikely for the jet to reach the internal face. Besides, the jet generated by the solid cone is evenly distributed, the droplets are large- and mediumsized, and the jet has good coverage performance.

\section{Simulation result and analysis}

\subsection{Solid-cone and hollow-cone models}

Figures 2-5 show the temperature nephograms and speed nephograms of the middle section of the burner chamber.

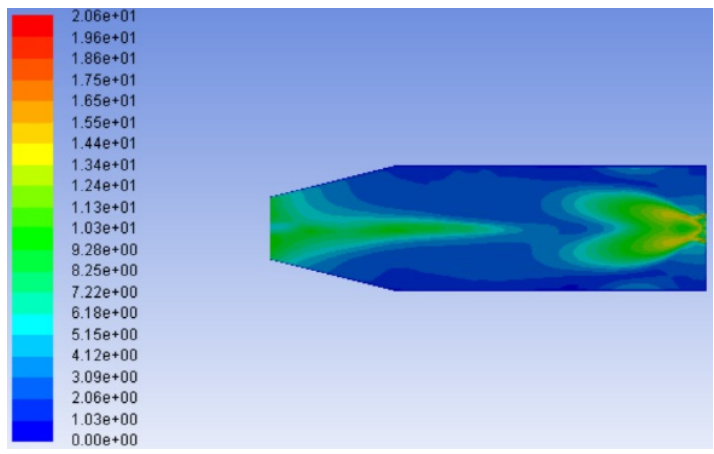

Figure 3. Speed nephogram (hollow cone model)

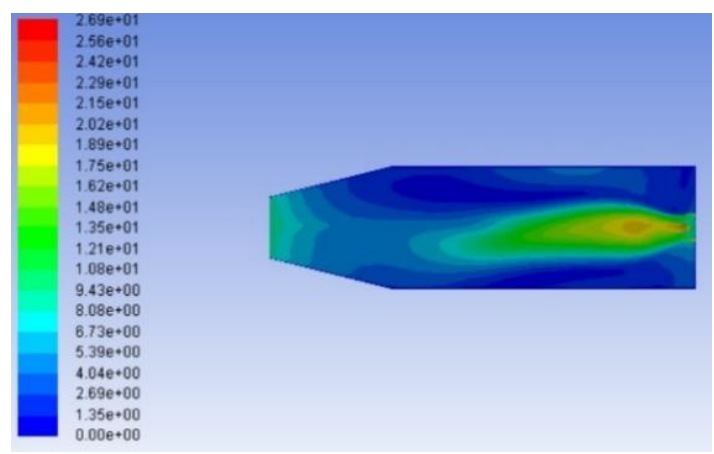

Figure 5. Speed nephogram (solid cone model)

\subsection{Spray angle}

The spray angle is the angle between the two tangent lines of the envelop curve of the spray at the nozzle. The size of the spray angle has a significant impact on the combustion efficiency and the economy of the wastewater disposal process. The temperature nephograms and the speed nephograms of the section of the burner chamber under different spray angles are shown in Figures $6-11$. 


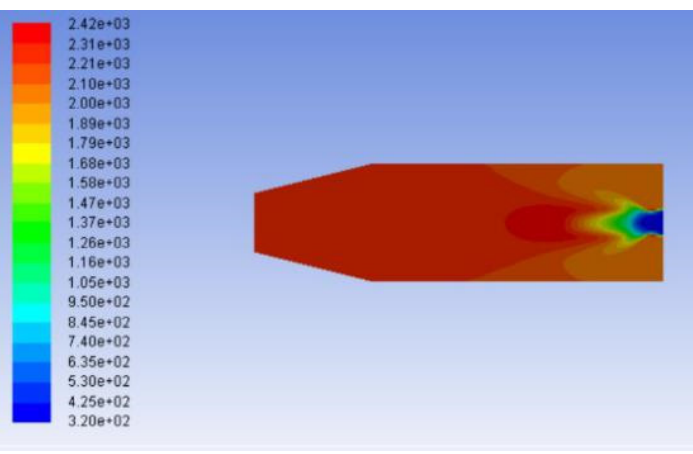

Figure 6. Temperature nephogram (spray angle $=30^{\circ}$ )

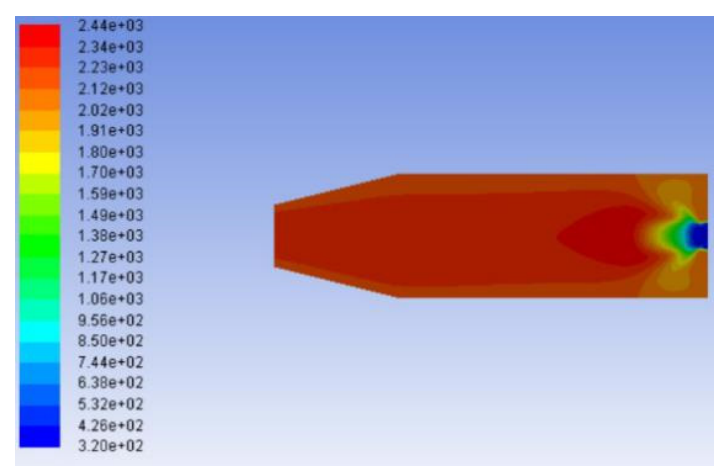

Figure 8. Temperature nephogram (spray angle $=50^{\circ}$ )

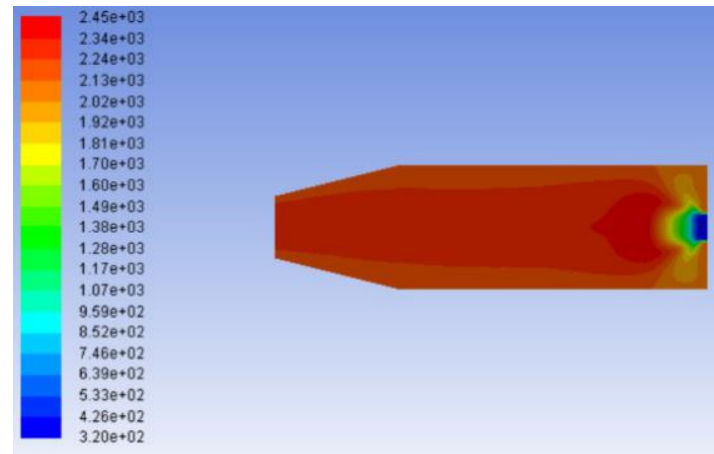

Figure 10. Temperature nephogram (spray angle $=70^{\circ}$ )

Under a small spray angle $\left(30^{\circ}\right)$, the droplets distribute unevenly around the nozzle, and the droplets do not cover the whole combustion area, which leads to insufficient blending with air in some regions and a large local air coefficient, reduces the combustion temperature at the inlet, and undermines the effect of ignition and combustion. As the spray angle increases, the distribution becomes even. When the spray angle is large $\left(70^{\circ}\right)$, some of the atomized liquid is sprayed on the surface of the burner chamber directly when it is sprayed, which leads to combustion attached to the wall and

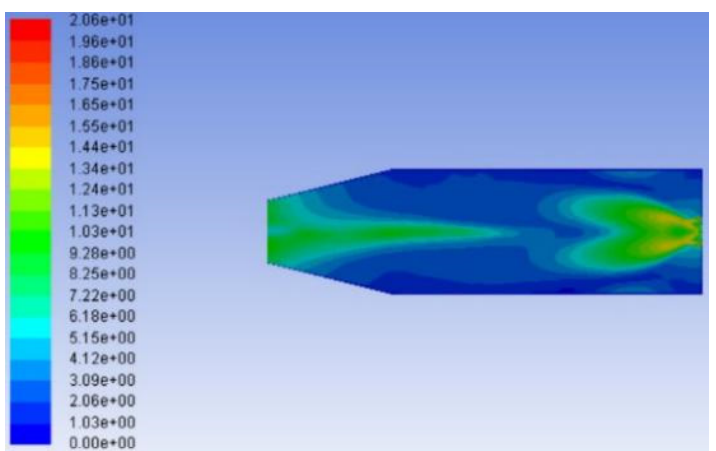

Figure 7. Speed nephogram ( spray angle $=30^{\circ}$ )

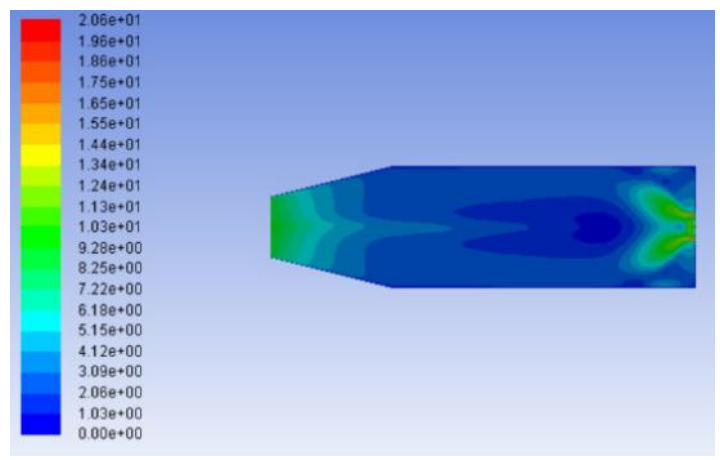

Figure 9. Speed nephogram (spray angle $\left.=50^{\circ}\right)$

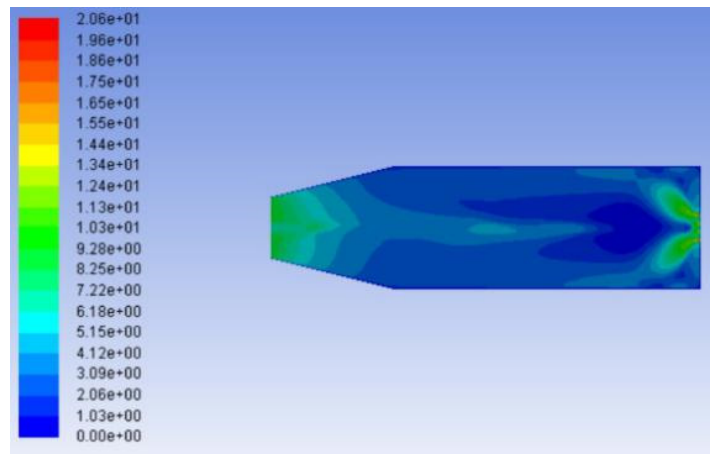

Figure 11. Speed nephogram (spray angle $\left.=70^{\circ}\right)$

affects the combustion efficiency. Thus, the spray angle should neither be too small nor too large.

\subsection{Uniform grain size and non-uniform grain size}

Figures 12-15 show the temperature nephograms and speed nephograms of the section of the combustion chamber non-uniform grain sizes. the maximum grain size is $140 \mu \mathrm{m}$, the minimum is $40 \mu \mathrm{m}$, and the mean is $80 \mu \mathrm{m}$, and there are 20 types of grain sizes. 


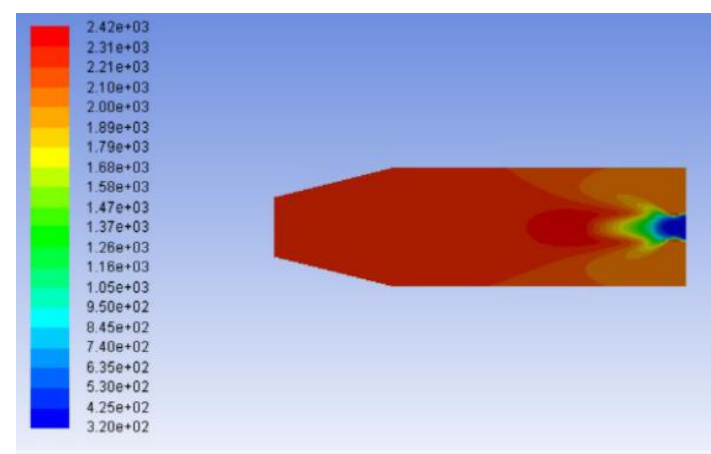

Figure 12. Temperature nephogram (uniform grain size $=80 \mu \mathrm{m})$

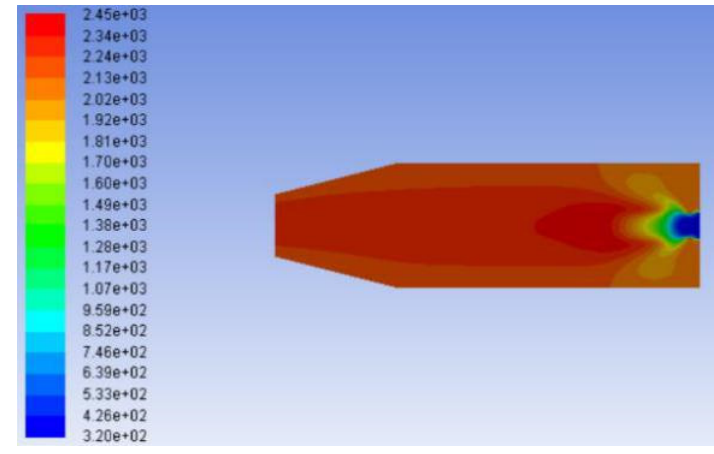

Figure 14. Temperature nephogram (non-uniform grain size)

The "uniform grain size" scenario assumes that all particles have the same diameter, but in most cases, the droplets consist of particles of different diameters. The "non-uniform" scenario shares many features of the different uniform grain sizes and is similar to the simulation scenario of uniform grain size distribution with the same average grain size. In these simulations, there are scenarios in which the droplets may not be fully combusted because of the excessively large grain size, and there are also scenarios in which the combustion is unstable because of insufficient mixture with air due to an excessively small grain size.

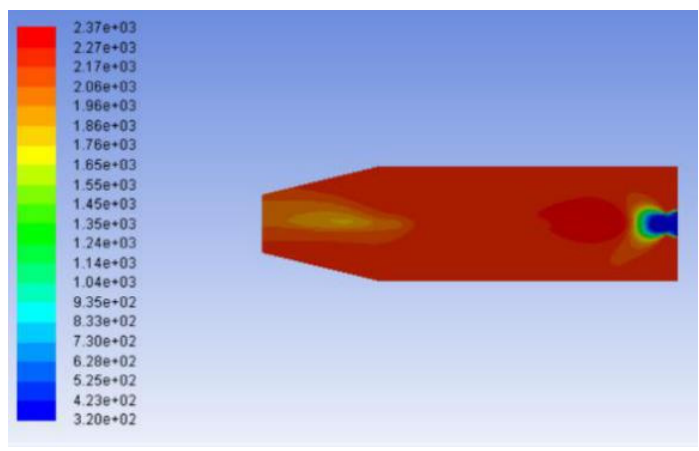

Figure 16. Temperature nephogram (uniform grain size $=40 \mu \mathrm{m}$ )

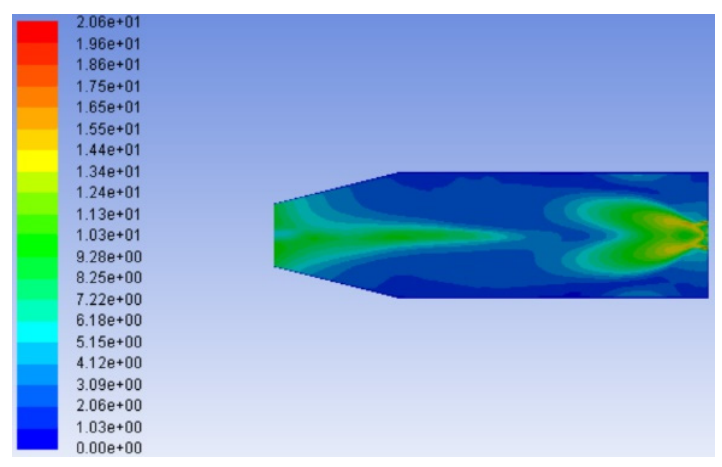

Figure 13. Speed nephogram

(uniform grain size $=80 \mu \mathrm{m}$ )

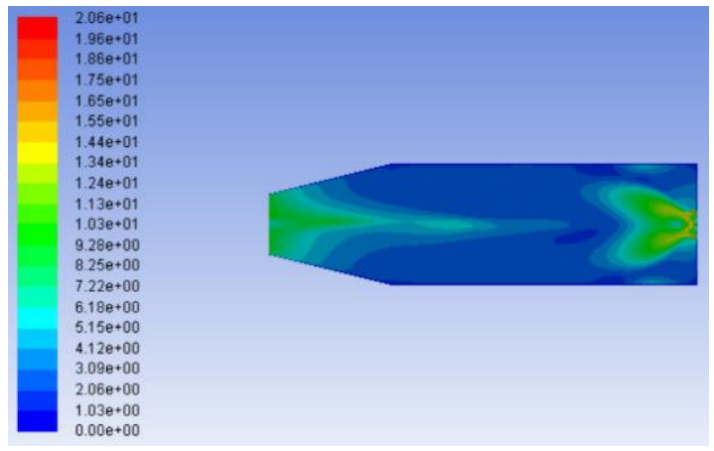

Figure 15. Speed nephogram (non-uniform grain size)

\subsection{Different uniform grain sizes}

The post-atomization granularity characterizes the size of the droplets in the atomized torch after the wastewater atomization.Four groups of grain sizes ranging from $40 \mu \mathrm{m}$ to $120 \mu \mathrm{m}$ are selected for simulation. Figure 16-23 show the temperature nephograms and speed nephograms of the section of the combustion chamber under different atomization grain sizes (spray angle $=30^{\circ}$ ).

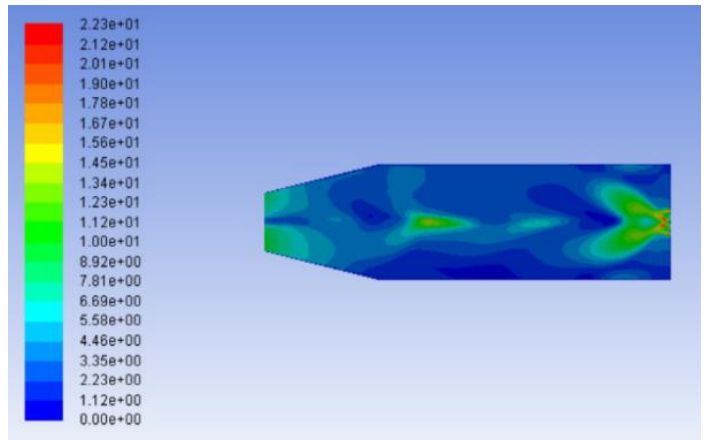

Figure 17. Speed nephogram (uniform grain size $=40 \mu \mathrm{m}$ ) 


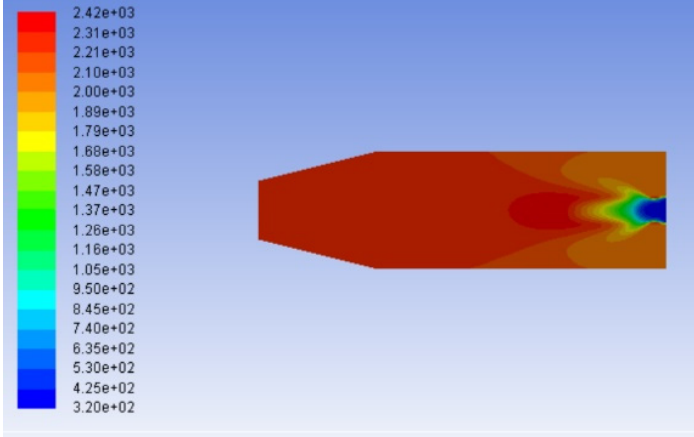

Figure 18. Temperature nephogram (uniform grain size $=80 \mu \mathrm{m}$ )

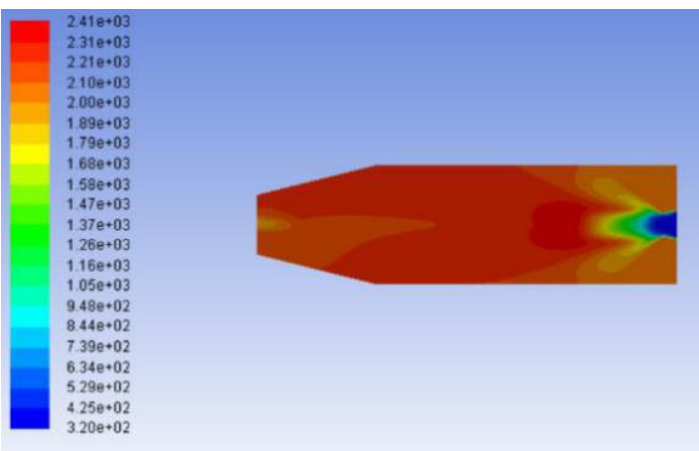

Figure 20. Temperature nephogram (uniform grain size $=100 \mu \mathrm{m}$ )

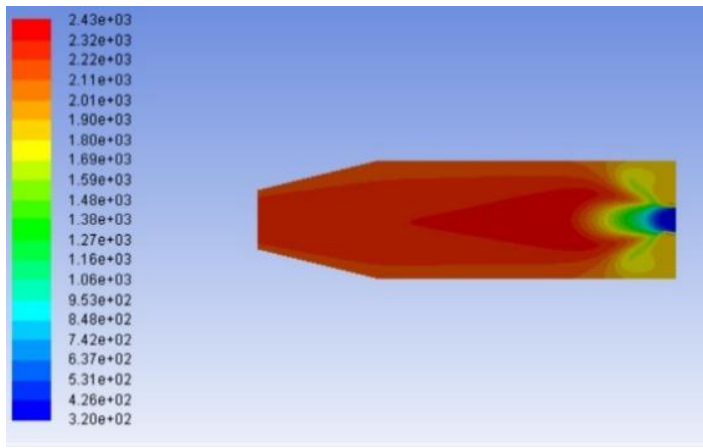

Figure 22. Temperature nephogram (uniform grain size $=120 \mu \mathrm{m}$ )

In terms of the speed and efficiency of combustion, the smaller the grain size is, the better. However, an excessively small grain size will lead to local concentration or shortage of fuel, and in the radial transmission process of the flame, the temperature field is unevenly distributed, and the maximum temperature drops, which indicates incomplete or unstable combustion. When the grain size increases, the speed is evenly distributed, which indicates stable transmission of the spray flow along the axial direction. Likewise, if the grain size cannot be too large. For instance, when the grain size is $120 \mu \mathrm{m}$, there is incomplete combustion in the temperature field, the recirculation region is not obvious, and the temperature around the inlet is low. Therefore, a proper grain size should be selected to ensure sufficient and stable combustion.

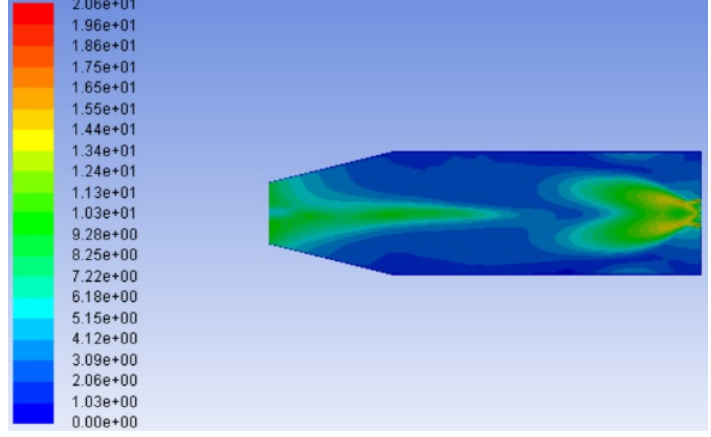

Figure 19. Speed nephogram (uniform grain size $=80 \mu \mathrm{m}$ )

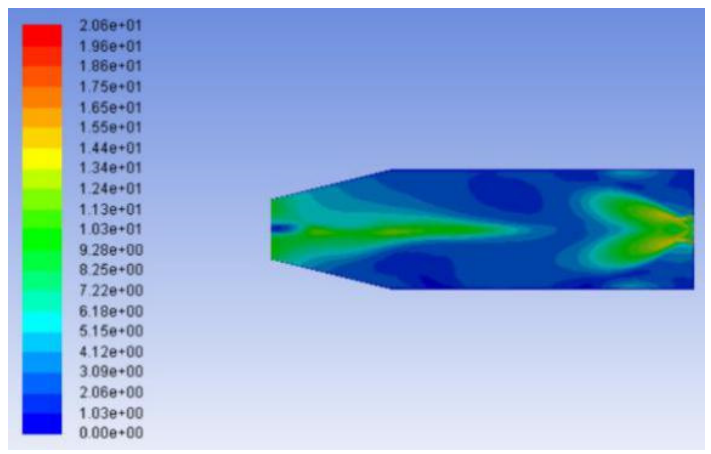

Figure 21. Speed nephogram (uniform grain size $=100 \mu \mathrm{m}$ )

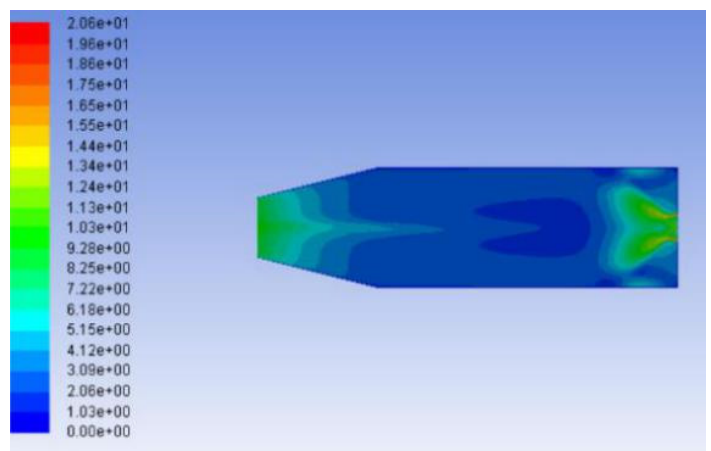

Figure 23. Speed nephogram (uniform grain size $=120 \mu \mathrm{m}$ )

\section{Conclusions}

The wastewater burner plays a crucial role in disposal of wastewaterr. In the present study, the Fluent software is employed to explore the impacts of atomization parameters on the combustion process. The major findings are as follows. The solid cone model has no hollowed space inside and boasts a better combustion effect than the hollowed cone model. The spray angle should be neither too large nor too small: if the angle is too large, a large amount of fuel droplets will be sprayed on the wall of the combustion chamber, leading to carbon deposition and insufficient combustion; if the angle is too small, the droplets will not be sprayed evenly in the flow field. Non-uniform grain size distribution resembles better the actual combustion process than the uniform grain size distribution, but it is also necessary to 
take into account the structure of the combustion device and the air flow conditions. The grain size of the atomized wastewater should neither be too large nor too small.

\section{Acknowledgments}

Special thanks to tutor Tang Qiang for his guidance, and younger martial brothers Zhang Tengfei for his great help in the process of numerical simulation, as well as other teachers and students of Institute for Energy and Environment Research of Chongqing University for their help and encouragement.

\section{References}

1. Jiang B. (2015) Numerical simulation of combustion of the wastewater burner. North China Electric Power University, Beijing.

2. Yin H.C., et al. (2015) Numerical simulation of the combustion process inside the wastewater burner and pollutant discharge characteristics. Journal of Thermal Science and Technology , 14(4): 297-304.

3. Patankar., et al. (1980) Numerical Heat Transfer and Fluid Flow. Hemisphere Publishing Co, New York.

4. Ran J.Y., et al. (2018) Numerical simulation of thermophysical process. China Electric Power Press, Beijing. 